\title{
REVIEW: H. van Ditmarsch, W. van der Hoek and B. Kooi's Dynamic Epistemic Logic
}

\author{
Patrick Girard \\ University of Auckland \\ p.girard@auckland.ac.nz \\ Received by Greg Restall \\ Published May 29, 2009 \\ http://www.philosophy.unimelb.edu.au/ajl/2009 \\ (C) 2009 Patrick Girard
}

van Ditmarsch, Hans, van der Hoek, Wiebe and Kooi, Barteld: Dynamic Epistemic Logic, Springer Verlag, 2007, 282 pp., USD\$175.00.

ISBN : $978 \mathrm{I} 402058387$.

\section{REVIEW}

Dynamic epistemic logic can be traced back to the works of Hintikka [9] and Pratt [16], but has been flourishing mostly since the turn of the millennium. Even so, a first textbook in the field is felt as having been long-awaited! If only for this reason, this book should be on any (modal) logician's bookshelf.

The main goal of the book is to analyze change of information in a logical setting. Information is treated as being held by agents in the form of knowledge, primarily, but also belief. A convenient way to think of the logical treatment of knowledge in this book is in a stratified way: I) static knowledge about permanent truths (tautologies or validities) and facts in particular situations, 2) knowledge for groups of agents in the form of common knowledge and 3) dynamics of knowledge with respect to incoming information. This stratification is reflected throughout the book in the various languages adopted, but also in the modular structures of the logics.

This manuscript is meant to be a graduate textbook, but a good background in modal logic in the recent Dutch tradition (cf., [6]) or a supportive instructor are strongly recommended. A decent background in modal logic should be a prerequisite in any case. The topics do not always seem to be presented in the best pedagogical order; references are often made to what will be presented later in the book and this might get a novice reader confused. The English is not always natural and fluctuates in quality depending on various sections or 
chapters. The relevence of the book to computer science is made more obvious than to philosophy, although the logics considered raise interesting challenges to mainstream epistemology, namely to incorporate dynamics in standard conception of knowledge. The book is thus lacking in philosophical motivations. The selection of puzzles and illustrations throughout the book, however, is very good and a great tool to assist the assimilation of the material. Each chapter in the book is self-contained (at least with respect to each other chapter and once the content of the first chapter is digested or, better, already assimilated). A course based on this textbook could thus pick any selection of chapters, depending on the course level or quality of students. For the modal logic expert who has not studied dynamic epistemic logic previously, this book is the place to start, although recent developments in the field should be consulted for a fuller picture.

In the rest of the review, I will first give a precis of each chapter (omitting the introductory Chapter I) and will then suggest additional material that is relevant or untouched in the book.

Chapter 2 gives the basic static system, which is the well-known (multi-) modal logic S5, but interpreted as epistemic logic, in the tradition following the seminal work of Hintikka [9]. Three additional group modalities are then introduced, with $A$ a group of agents: I) shared knowledge, written $E_{A} \varphi$ 2) distributed knowledge, $D_{A} \varphi$ and 3 ) common knowledge, $C_{A} \varphi$. The first is defined as the conjunction and the second as the disjunction of each agent knowing that $\varphi$, with intended interpretation that every agent knows that $\varphi$ and that the group of agent knows that $\varphi$ by combining their knowledge. Common knowledge is a more complex modality and is defined, following Lewis [II], as the limiting case of shared knowledge embeddings: everybody knows that everybody knows that ... everybody knows that $\varphi$. This latter modality plays a central role in the remaining chapters and is fully analyzed dynamically. The dynamics of common knowledge is probably the main contribution of the dynamic epistemic logic paradigm.

Chapter 3 is concerned with belief change and the now well-established paradigm of belief revision known as AGM initiated in [I]. AGM analyzes belief change in terms of 3 actions: I) expansion, 2) revision and 3) contraction of a belief set with a formula $\varphi$. The AGM approach is primarily postulational, in the sense of providing a set of postulates taken to be rational guidelines for belief change. For instance, the success postulate states that $\varphi$ should be in the set obtained after revising a belief set with $\varphi$. These postulates, however, do not describe nor prescribe a unique belief change operator, and the most common proposal found in the literature, that of maxichoice, is presented. The chapter then turns to Segerberg's formalization of AGM in a logical setting, known as dynamic doxastic logic (DDL, cf., [I2] for a recent exposition with references to previous iterations). DDL is a mixture of conditional doxastic logic interpreted in sphere systems with dynamic modalities, one for each of the AGM actions. This chapter is the most independent from other chapters, and is 
the only one that focuses on beliefs. The DDL system is probably what provides the strongest link to the rest of the book, but the chapter would benefit from modern treatments of belief change which would integrate it better in the monograph.

Chapter 4 is a thorough investigation of public announcement logic (cf., [I5]) and is the exemplar chapter of dynamic epistemic logic. It is by far the most important chapter for new comers to the discipline. Public announcement is the action of truthfully announcing $\varphi$. As opposed to the AGM postulational approach, public announcement is treated in a constructive approach and is a fully prescribed action on epistemic models. The action of announcing $\varphi$ is quite simple: delete all the $\neg \varphi$-states along with accessibility relation to and from these states, but keep the remaining submodel intact. Interesting results with respect to announcements pertain to so-called unsuccessful updates, those announcements of $\varphi$ such that $\varphi$ is false after the announcement. A typical example is a Moore-type sentence $\psi=\varphi \wedge \neg K_{a} \varphi$ ( $\varphi$ is true but you don't know it), which can only be performed in states where indeed $\varphi$ is true and you don't know it, but $\psi$ becomes false after the announcement. This kind of discussion becomes all the more interesting in the presence of common knowledge and a detailed presentation of the issues is provided. The chapter closes with 3 simple, but rich, puzzles: I) Muddy children, 2) Sum and Product and 3) Russian Cards.

Chapter 5 presents a generalization of the language of public announcement with learning operators, combined with other PDL operators, resulting in a rich language - so rich that it is still unknown how to axiomatize it, unfortunately. This chapter is more difficult (both in content and in reading) than the other chapters and it is advisable to skip to Chapter 6 in an introductory course.

Chapter 6 is the alter-ego of Chapter 4 and presents the other most influential logic in the recent development of DEL. This logic is now known as BMs, after it's authors names (cf., [5]) and this chapter gives it full justice with a full and clear exposition. вмs is a component-wise analysis of static states and epistemic actions. It is an alternative generalization of public announcement logic to the epistemic action system of Chapter 5 which also allows to express complex actions such as private announcement, cheating, learning, etc. BMS has lead to a lot of research recently and I will give some pointers to companion readings for this chapter below.

Chapter 7 is a technical excursion in the completeness results of the various logics studied in previous chapters. It works with a standard canonical model construction or an adaption of the latter construction for non-compact logics (those involving common knowledge). Of notice is the method repeatedly used and sometimes known as 'compositional analysis via reduction axioms', which allows the recursive elimination of action modalities in arbitrary formulas, thus 
the reduction of completeness of the dynamic logic to that of the static one. This technique has been applied many times in other dynamic logics of belief and preferences.

Finally, Chapter 8 presents a second technical excursion on the relative expressivity of the various languages used in the book. The results discussed are based on an (obvious) adaptation of Ehrenfeucht-Fraïssé games to modal logic. For instance, it is shown that S5 plus public announcement is equally expressive to $S 5$ without public announcement (which can also be seen via the completeness result with compositional analysis mentioned above), but that $\mathrm{S5}$ plus common knowledge is more expressive than $S 5$ without common knowledge. Surprisingly, the logic $\mathrm{K}$ with common knowledge is equally expressive to the logic $\mathrm{K}$ with common knowledge and public announcement, although the result is not know in the case of S5. This is an interesting question to be solved by the interested reader or even for graduate students!

A recent development in belief revision, briefly mentioned in the book but which deserves greater attention, is [18]. This paper presents a formalization of belief revision as a proper model change in the constructive approach alluded to above. The axiomatization and completeness uses compositional analysis, which is more in the spirit of the rest of the book. A similar dynamic treatment of preferences can be found in [20]. These two papers show two important kinds of dynamics to be performed on models, in addition to the world deletion of public announcement, namely world reordering (belief revision) and accessibility link deletion (preference upgrade). For an adaptation of the вмS system to belief revision, which would enrich Chapter 3 greatly, see also [2] and further references given there.

Complexity issues pertaining to public annoucement can be found in [I4]. Similar complexity questions for the belief revision and preference upgrade actions are still open. A recent and fruitful generalization of the action of public announcement to an action of arbitrary announcement can be found in [4].

Temporal logic (cf., [IO]) is not considered in the book, but is an important facet of dynamics. The BMs system is a good starting point to introduce temporal structure in dynamic epistemic logic, as the succession of action is fully encoded in the states. An extended language with a past looking modality, increasing the expressivity of the system, can be found in [2I]. A good comparison with epistemic temporal logic (ETL) can be found in [I9].

Recent $\mathrm{Ph} . \mathrm{D}$. dissertations have been written in the tradition under which the book under review has been written. The reader will find additional references and alternative approaches there. These are [3], [7] , [13] and [i] $]$.

For the more philosophical reader, a comparison of mainstream and formal epistemology, in particular the role of logic, can be found in [8]. A more thorough comparison of dynamic epistemic logic and mainstream epistemology and the influence that a dynamic twist could have in epistemology is still awaiting. 


\section{REFERENCES}

[i] Carlos eduardo alchourrón, peter gärdenfors, and david MAKINSON. On the logic of theory change: partial meet contraction and revision functions. The journal of symbolic logic, 50:510-530, 1985.

[2] Guillaume aucher. A combined system for update logic and belief revision. Master's thesis, Institute for logic, language and computation, 2003.

[3] Guillaume aucher. Perspective on belief and change. PhD thesis, University of Otago and Université Toulouse I I - Paul Sabatier, 2008.

[4] P. balbiani, A. Baltag, H. P. VAN Ditmarsch, A. HeRzig, T. hoshi, and T. DE Lima. 'Knowable' as 'known after an announcement'. Review of symbolic logic, 2009 .

[5] A. baltag, L. s. moss, and s. solecki. The logic of public announcements, common knowledge and private suspicions. In TARK 98, 1998.

[6] patrick blackburn, maarten de rijke, and yde venema. Modal Logic. Cambridge University Press, Cambridge, $200 \mathrm{I}$.

[7] Patrick Gi Rard. Modal logic for belief and preference change. PhD thesis, Stanford University, 2008.

[8] vincent f. Hendricks. Mainstream and formal epistemology. Cambridge university press, 2006.

[9] JаA к ко н іnтік ка. Knowledge and Belief: An Introduction to the Logic of Troo Notions. Cornell University Press, Ithaca, N.Y., 1962.

[IO] I. HODKINSON and M. REYNOLDS. Temporal logic. In P. BlaCKBURN, J. VAN BENTHEM, and F. WOLTER, editors, Handbook of modal logic. Elsevier, 2007.

[II] DAVID LEwis. Convention. Blackwell, 2002.

[i2] Sten lindström and krister Segerberg. Modal logic and philosophy. In PATRICK BLACKBURN, JOHAN VAN BENTHEM, and FRANK wOLTE R, editors, Handbook of Modal Logic, volume 3, pages II49-I2I4. Elsevier, 2007.

[i3] fenrong liu. Changing for the Better: Preference Dynamics and Agent Diversity. $\mathrm{PhD}$ thesis, Institute for logic, language and computation (ILLC), 2008.

[i4] Carsten lutz. Complexity and succinctness of public announcement logic. In Proceedings of the Fifth International Conference on Autonomous Agents and Multiagent Systems (AAMA S O6), 2006. 
[I5] J. A. Plaza. Logics of public communications. In M. L. EMRICH, M. S. Pfeifer, M. HADZiKadic, and z. w. RAs, editors, Proceedings of the 4 th international symposium on methodologies for intelligent systems, pages $2 \mathrm{OI}-2 \mathrm{I} 6$, I989.

[i6] v. R. Pratt. Semantical considerations on Floyd-Hoare logic. In Proc. 2oth I E EE symposium on computer science, pages IO9-I2I, 1976.

[I7] OLIVIE R ROy. Thinking before Acting: Intentions, Logic, Rational Choice. $\mathrm{PhD}$ thesis, Institute for logic, language and computation (ILLC), 2008.

[i8] johan van benthem. Dynamic logic for belief revision. Fournal of $A p$ plied Non-classical Logic, I7(2):129-155, 2007.

[I9] JOHAN VAN BENTHEM, JELLE GERBRANDY, TOMOHIRO HOSHI, and ERIC PACU IT. Merging frameworks for interaction. Founral of philosophical logic, 2009.

[20] JOHAN VAN BENTHEM and FenRong LiU. The dynamics of preference upgrade. Fournal of Applied Non-Classical Logics, I7(2):157-I82, 2007.

[2I] AUdRey yap. Product update and looking backward. Technical report, ILLC, Prepublication Series, PP-2006-39, 2006. 
The Australasian fournal of Logic (ISSN I448-5052) disseminates articles that significantly advance the study of logic, in its mathematical, philosophical or computational guises. The scope of the journal includes all areas of logic, both pure and applied to topics in philosophy, mathematics, computation, linguistics and the other sciences.

Articles appearing in the journal have been carefully and critically refereed under the responsibility of members of the Editorial Board. Only papers judged to be both significant and excellent are accepted for publication.

The journal is freely available at the journal website at

$$
\text { http://www.philosophy.unimelb.edu.au/ajl/ }
$$

All issues of the journal are archived electronically at the journal website.

Subscriptions Individuals may subscribe to the journal by sending an email, including a full name, an institutional affiliation and an email address to the managing editor atajl-editors@unimelb.edu.au. Subscribers will receive email abstracts of accepted papers to an address of their choice. For institutional subscription, please email the managing editor atajl-editors@unimelb.edu.au

Complete published papers may be downloaded at the journal's website at http: //www.philosophy.unimelb.edu.au/ajl/ The journal currently publishes in pdf format.

Submission The journal accepts submissions of papers electronically. To submit an article for publication, send the $\mathrm{LT}_{\mathrm{E}} \mathrm{X}$ source of a submission to a member of the editorial board. For a current list of the editorial board, consult the website.

The copyright of each article remains with the author or authors of that article. 